\title{
Diffusion of carbon in substitutionally alloyed austenite
}

\author{
S. S. BABU\#, H. K. D. H. BHADESHIA \\ University of Cambridge/JRDC, Department of Materials Science and Metallurgy, Pembroke Street, Cambridge \\ CB2 3QZ, UK
}

It is well known that the diffusion coefficient $D$ of carbon in austenite varies with the concentration of carbon $[1,2]$. In a previous analysis, it was demonstrated that a theory due to Siller and McLellan $[3,4]$ can adequately explain the experimental data for $\mathrm{Fe}-\mathrm{C}$ alloys in the austenitic condition over a wide range of concentration and temperature.

The theory represents $D$ in a way which is compatible with both the kinetic and thermodynamic behaviour of carbon in austenite. There are two important factors: the concentration dependence of the activity of carbon in austenite $[1,2]$ and the existence of a finite repulsive interaction between nearest neighbouring carbon atoms situated in octahedral sites [5]. Smith [2] has demonstrated that the composition dependence of activity cannot alone account for $D$. Siller and McLellan realized that the repulsive forces between neighbouring carbon atoms should influence diffusivity by acting to reduce the probability of interstitial site occupation in the vicinity of a site already containing a carbon atom. In a concentration gradient, a carbon atom attempting random motion therefore 'sees' an exaggerated difference in the number of available sites in the forward and reverse direction, so that diffusion down the gradient is enhanced. On this basis, Siller and McLellan obtained

$$
D\left\{x_{1}, T\right\}=(k T / h)\left(\exp \left\{-\Delta F^{*} / k T\right\}\right)\left(\lambda^{2} / 3 \Gamma_{m}\right) \eta\{\theta\}
$$$$
\text { , }
$$

with

$$
\begin{aligned}
& \frac{\eta\{\theta\}}{a_{1}^{\gamma}}=1+ \\
& {\left[\frac{W(1+\theta)}{1-(0.5 W+1) \theta+\left(0.25 W^{2}+0.5 W\right)(1-\phi) \theta^{2}}\right]} \\
& +(1+\theta) \frac{1}{a_{1}^{\gamma}}-\frac{\mathrm{d} a_{1}^{\gamma}}{\mathrm{d} \theta}
\end{aligned}
$$

where $k$ and $h$ are the Boltzmann and Planck constants, respectively, $W$ is the number of octahedral interstices around a single such interstice, $\Delta F^{*}$ is an activation free energy, $\Gamma_{m}$ is an activity coefficient and $\lambda$ is the distance between (002) austenite planes. $\phi=1-\exp \left(-\omega_{y} / k T\right) ; \omega_{\gamma}$ is the nearest neighbour carbon-carbon interaction energy in austenite. $\theta$ is the ratio of the number of carbon atoms to the total number of solvent atoms, given by $\theta=x_{1} /\left(1-x_{1}\right)$. Bhadeshia [6] found $\Delta F^{*} / k=21230 \mathrm{~K}$ and $\ln \left\{\Gamma_{m} / \lambda^{2}\right\}=31.84$.

It clearly is possible for the same equation to be used for austenite containing substitutional solutes as well as carbon, if the sole effect of the substitutional solute is to influence the activity of the carbon. The purpose of this work was to demonstrate that this is indeed the case, using published data [7].

These data reveal quite significant changes in the mobility of carbon as a function of the substitutional solute; some of the data are listed in Table I for illustration purposes. For example, nickel and aluminium have a rather small effect when compared with plain carbon steel, whereas chromium and molybdenum tend to reduce the diffusivity.

The effects clearly are significant and were analysed using the Siller and McLellan model. The activity coefficient for carbon in alloyed austenite was calculated using the quasichemical thermodynamic model developed in [8]. In this, the activity of carbon depends on the partial molar enthalpy of solution of carbon in austenite $\left(38575 \mathrm{~J} \mathrm{~mol}^{-1}\right)$, and on the partial non-configurational entropy of solution of carbon in austenite $\left(13.48 \mathrm{~J} \mathrm{~mol}^{-1} \mathrm{~K}^{-1}\right)$ [8]. In addition, there is a carbon-carbon interaction energy which depends on the substitutional solute as well, and was obtained from [9]. This model is restricted to small concentrations, but diffusion data

\begin{tabular}{|c|c|c|c|c|c|}
\hline $\boldsymbol{X}$ & Wt $\% \mathbf{X}$ & Wt \% C & $\begin{array}{l}D\left(1000^{\circ} \mathrm{C}\right) \\
\left(10^{7} \mathrm{~cm}^{2} \mathrm{~s}^{-1}\right)\end{array}$ & $\begin{array}{c}D\left(1100^{\circ} \mathrm{C}\right) \\
\left(10^{7} \mathrm{~cm}^{2} \mathrm{~s}^{-1}\right)\end{array}$ & $\begin{array}{c}D\left(1200^{\circ} \mathrm{C}\right) \\
\left(10^{7} \mathrm{~cm}^{2} \mathrm{~s}^{-1}\right)\end{array}$ \\
\hline - & - & & 2.21 & 6.12 & 14.85 \\
\hline $\mathrm{Ni}$ & 4 & & 2.65 & 6.54 & 14.05 \\
\hline $\mathrm{Cr}$ & 2.5 & & 0.41 & 1.19 & 2.81 \\
\hline Mo & 1.55 & & 1.85 & 5.01 & 11.6 \\
\hline Co & 6 & & 3.9 & 9.3 & 16.7 \\
\hline Al & 0.7 & & 2.7 & 6.6 & 14.4 \\
\hline
\end{tabular}
over the following concentrations (wt $\%$ ) were

TABLE I Selected coefficients for the diffusion of carbon in austenite. The data for the alloy steels are from [7] whereas those for the plain carbon steel are from [6] 
nevertheless investigated: $\mathrm{Ni}(4,9.5), \mathrm{Mn}(1), \cdot \mathrm{Co}$ (6), Cr $(1,2.5,7)$, Mo $(0.9,1.55)$, W $(0.5,1.05$, 1.95), $\mathrm{Si}(1.6,2.55)$ and $\mathrm{Al}(0.7,1.7,2.45)$. Data for three different carbon concentrations $(0.2,0.4$, $0.7 \mathrm{wt} \%$ ) were available in each case.

The results are illustrated in Figs 1-8. The model in general gives good results, the most severe discrepancies being found for chromium steels. The alloys studied [7] were checked to be fully austenitic at the temperature where the measurements were made, by comparison against published phase diagrams [10]. There is a slight danger of alloy carbide formation for the $\mathrm{Fe}-0.7 \mathrm{C}-7.0 \mathrm{Cr}$ wt $\%$ alloy at $1000^{\circ} \mathrm{C}$, but in all other cases, the alloys should be fully austenitic. It also cannot be argued that it is the

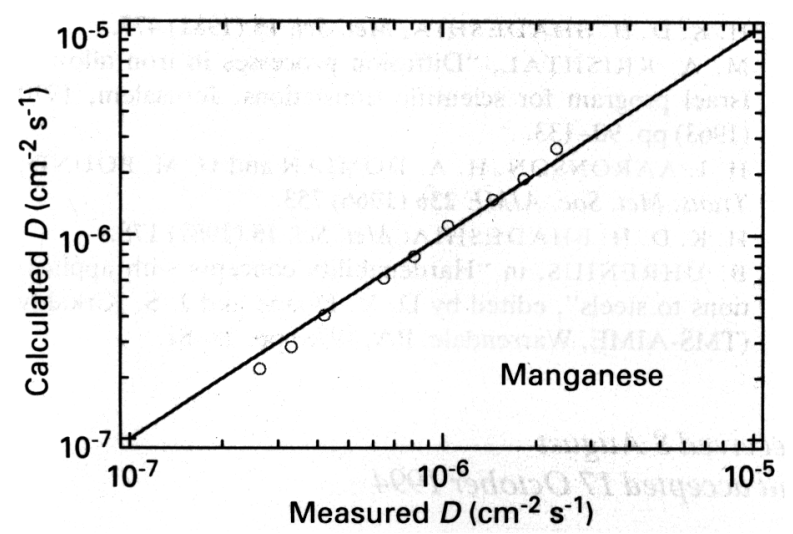

Figure 1 Comparison of the calculated and measured diffusivities for $\mathrm{Fe}-\mathrm{Mn}-\mathrm{C}$ alloys.

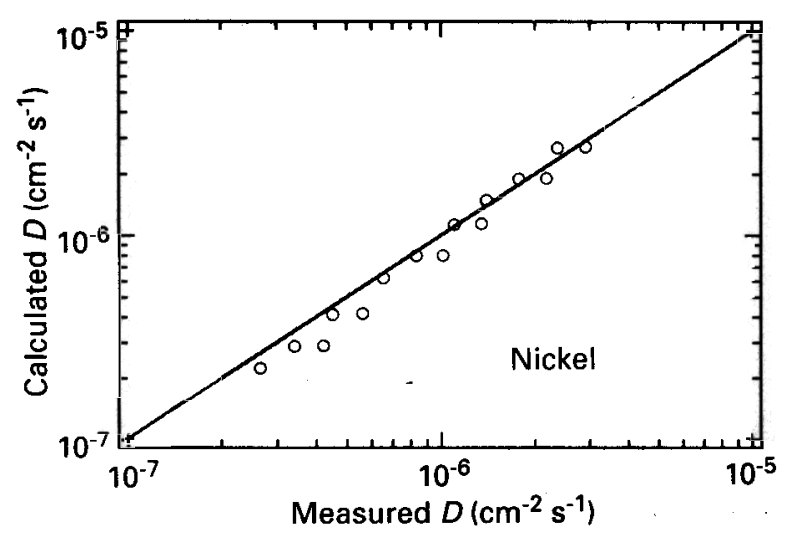

Figure 2 Comparison of the calculated and measured diffusivities for $\mathrm{Fe}-\mathrm{Ni}-\mathrm{C}$ alloys.

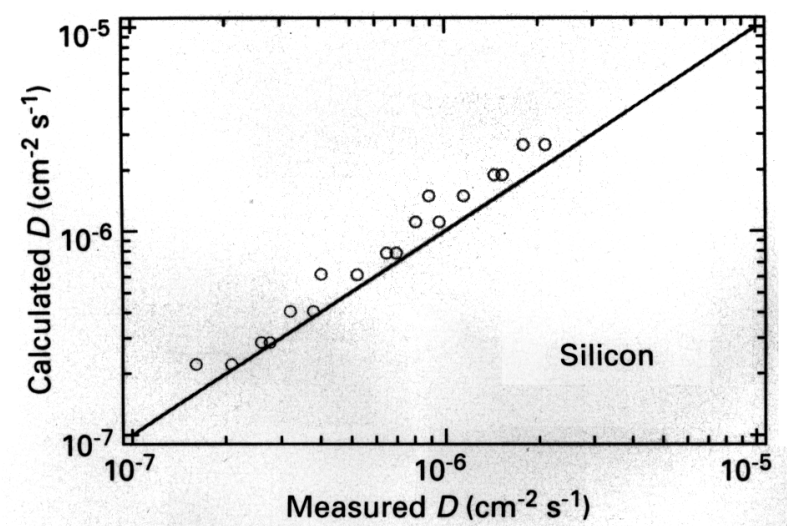

Figure 3 Comparison of the calculated and measured diffusivities for $\mathrm{Fe}-\mathrm{Si}-\mathrm{C}$ alloys.

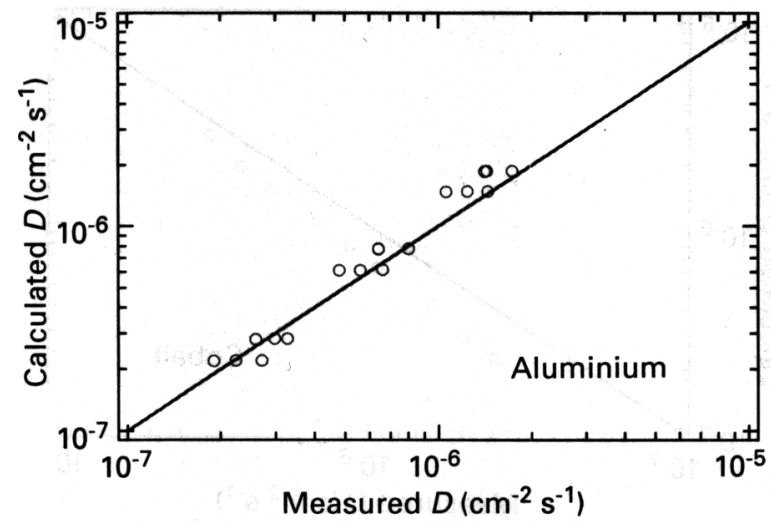

Figure 4 Comparison of the calculated and measured diffusivities for $\mathrm{Fe}-\mathrm{Al}-\mathrm{C}$ alloys.

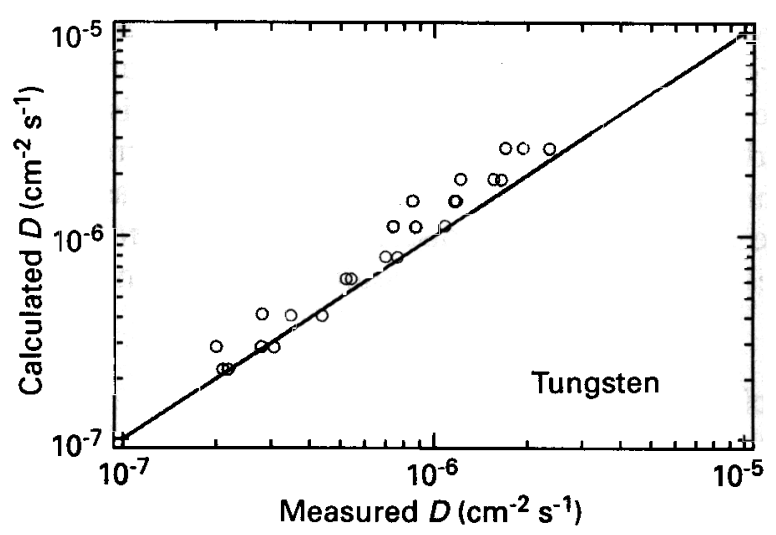

Figure 5 Comparison of the calculated and measured diffusivities for $\mathrm{Fe}-\mathrm{W}-\mathrm{C}$ alloys.

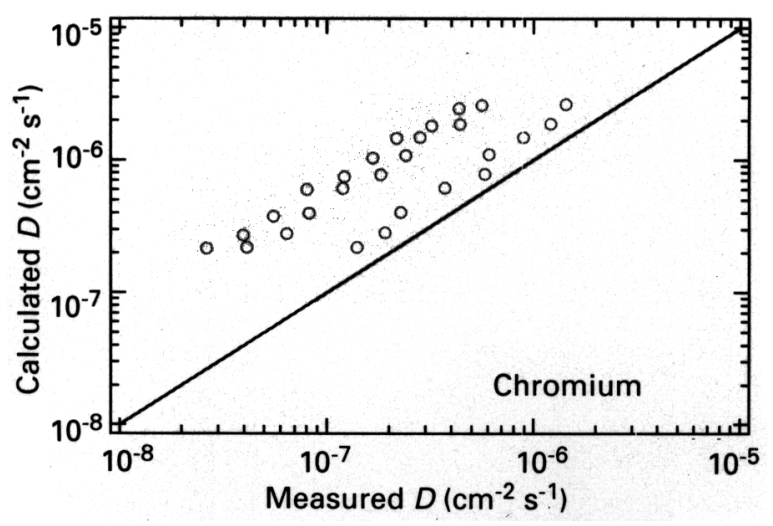

Figure 6 Comparison of the calculated and measured diffusivities for $\mathrm{Fe}-\mathrm{Cr}-\mathrm{C}$ alloys. The discrepancy increases with the chromium concentration.

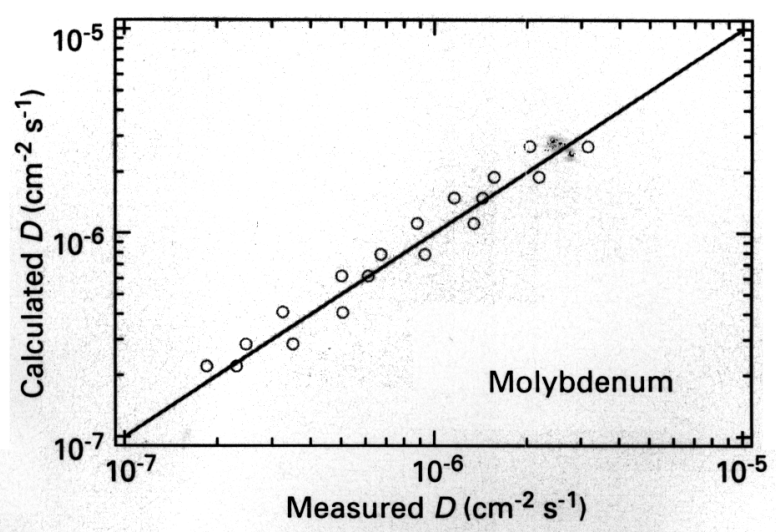

Figure 7 Comparison of the calculated and measured diffusivities for $\mathrm{Fe}-\mathrm{Mo}-\mathrm{C}$ alloys. 


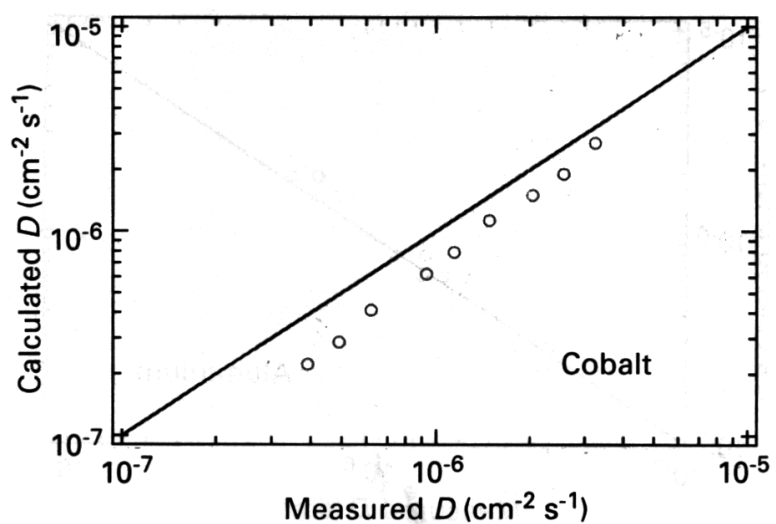

Figure 8 Comparison of the calculated and measured diffusivities for $\mathrm{Fe}-\mathrm{Co}-\mathrm{C}$ alloys.

strong carbide-forming elements which give the largest discrepancies, since the molybdenum data are well predicted. Indeed, silicon which is not a carbide former in steels has a (smaller) discrepancy which is similar to that of chromium. The reason for the large chromium discrepancy is therefore not clear and warrants experimental investigation.

\section{Acknowledgements}

The authors are grateful to the Ministry of Education, Taiwan for financial support and to Professor
Colin Humphreys for the provision of laboratory facilities. HKDHB's contribution was under the auspices of the 'Atomic Arrangements: Design and Control Project' which is a collaborative venture between the University of Cambridge and the Research and Development Corporation of Japan.

\section{References}

1. R. P. SMITH, J. Amer. Chem. Soc. 68 (1946) 1163.

2. R. P. SMITH, Acta Metall. 1 (1953) 579.

3. R. H. SILLER and R. B. McLELlAN, Trans. Met. Soc. AIME 245 (1969) 697.

4. R. H. SILlER and R. B. McLELlAN, Metall. Trans. 1 (1970) 985 .

5. R. B. McLellan and W. W. DUNn, J. Phys. Chem. Solids 30 (1969) 2631.

6. H. K. D. H. B HADESHIA, Met. Sci. 15 (1981) 477.

7. M. A. KRISHTAL, "Diffusion processes in iron alloys", Israel program for scientific translations, Jerusalem, 1970 (1963) pp. 90-133.

8. H. I. AARONSON, H. A. DOMIAN and G. M. POUND, Trans. Met. Soc. AIME 236 (1966) 753.

9. H. K. D. H. B HADESHIA: Met. Sci. 15 (1981) 178.

10. B. UHRENIUS, in "Hardenability concepts with applications to steels", edited by D. V. Doane and J. S. Kirkaldy (TMS-AIME, Warrendale, PA, 1978) pp. 28-81.

\section{Received 8 August}

and accepted 17 October 1994 